\title{
Formation of Training Environment by Means of Didactic Design
}

\author{
http://dx.doi.org/10.3991/ijep.v3i1.2297 \\ E.A. Vakhtina ${ }^{1}$, A.V. Vostrukhin ${ }^{2}$ \\ ${ }^{1}$ FSBEE HPE Stavropol State Agrarian University, Stavropol, Russia \\ ${ }^{2}$ FSBEE HPE Stavropol Technology Institute of Service, Stavropol, Russia
}

\begin{abstract}
Recent studies have argued the necessity of revealing pedagogical conditions in the university educational process for formation of the future engineers' readiness to productive and innovative activity. Training environment creates the system of pedagogical conditions and effects on the development of student qualities. We offers the didactic design as a technology for formation and development process management for future engineers by creation of training environment of the given quality. This technology has the spiral phase organization: modeling, designing, constructing and operation. The application of the didactic design on the example of the educational resource for programming microcontroller is considered. The submitted technology develops modern engineering educational practice in the field of creation of the developing training environment.
\end{abstract}

Index Terms-Engineering education, Didactic design, Didactic system, Electronics, Microcontroller, Educational resource.

\section{INTRODUCTION}

Engineering education represents now the most scale subsystem of higher vocational education in Russia and abroad. There is a tendency of increasing youth demand for engineering specialties. However, despite large-scale preparation of engineers, there is a shortage of specialists in high technologies and the highly technological industry. This deficiency will grow according to forecasts of the US and Japanese experts. World's leading countries sound the alarm that the national systems of vocational education do not satisfy the full demand for the engineering staff in the market of intellectual work both on a quantitative, and, especially on a qualitative level [1].An objective factor of this problem is education system inertness (delay) in relation to engineering practice. Acceleration of occurrence of new jobs in engineering and new tasks within traditional engineering, decreasing innovation cycles, exponential growth of the new technical information amount is observed [2].

We have defined the determination of pedagogical conditions in university educational process for formation of the future engineers' readiness to productive and innovative activity as the problem of the research.

In order to solve it we have addressed to a phenomenon of culture - design. Let's explain why.

As the system of influences and conditions of personality formation and development in social and spatialobjective environment of educational process is defined by the training environment it becomes the subject matter of our research. In new information status of the society this environment has passed to new qualitative level information-educational one, which differs from the traditional level in granting new tools, formation of other interaction space for students and teachers.

The analysis of scientific and pedagogical discourse of scientists of the late 20th - early 21 st centuries which subject was the educational environment revealed, that this environment is considered, first of all, as student support system in mastering multidimensional knowledge and multifunctional skills necessary for successful professional work [3, 4]. Efficiency of this system is provided with skilful integration into time and space of such systems as culture, policy and technologies of training [5, 6]. Contemporary researches of educational environment are characterized by the technological approach and orientation on development of the personal creativity [7, 8].

As it is known the educational environment is a derivative of culture. There design is used for formation of environment with specified properties. The designer works toward creation of the complete, harmonious, artistic high-grade object environment for human vital activity. Education is one of the components of this vital activity. Therefore the natural continuation of design development is replenishment of its basic directions: industrial, architectural, landscape, textile and others with didactic design. There were all conditions for its occurrence: level of modern science and technics development, requirements of professional and educational societies. Vivid example of didactic design establishment is formation of the educational environment within the limits of universal cultural space of the Internet. There is the integration of engineering (engineering methods of constructing and designing), system-related activity (technological) approach in pedagogic and achievements of pedagogical sociology and psychology. Behaviourism (B.F. Skinner) [9], cognitive psychology (B.S. Bloom., J. Piaget, R.C. Clark) $[10,11,12]$, social constructivism (L.S. Vygotsky, J.S. Bruner, A.S. Palincsar ) [13, 14, 15], connectivism (G. Siemens ) [16], the theory of contextual training (A.A. Verbitsky) [17], didactic multidimensional instruments (V.E. Steinberg) [18], etc. can be considered as the basic theoretical and methodological harbingers of didactic design.

Design in education extrapolates methods and means of design culture to all levels of vocational training with the purpose of their optimization [19].

Why is design chosen as a methodological platform for realization of modern competency-based approach in 
PAPER

Formation of Training ENVIRONMENT By MEANS OF DidACTIC DESIGN

engineering education? Analyzing the opinions of the leading experts in the field of educational psychology andtechnology $[14,17,18,19,20,21,22,23]$ it is possible to mark out the following productive for didactic system aspects of design.

The first one is the designing experience in modeling of complex objects in conditions of polyparadigm, causing action of approaches system: organizational, functional, activity-based, system-environment and culture-creative.

The second one is designer's experience of carrying out several professional functions: research, designing, methodical, organizational. During their realization it is necessary to unite efforts of various experts and the organizations, directed at creation of the system object.

Thirdly, it is necessary to underline essentially innovative character of the design activity aimed at creation of new objects, processes and systems with new properties, i.e. designing of a new reality. Positive changes of the indicators of human life quality serve as the main criterion of decision-making efficiency. Synthesis of design and engineering promotes a humanization of innovative technologies, creates essentially new design-culture with the person and its requirements, instead of the technique and technologies in its centre. Carrying over the designing technology of innovative objects, processes and systems into education will allow constructing new educational reality, aimed at creation of conditions for a growth of the indicators of education quality.

Fourthly, the design creates not only material, but also cultural values. It inherits and aesthetically transforms achievements of the previous culture. This is important for an education system in respect of continuity in development, formation of aesthetic tastes and the preferences, new requirements, cultural norms and valuable installations of the learning person through harmonization of the educational environment. There are principal causes which deduce design on a leading place in a choice of a methodological platform for realization of the competency-based model in engineering education.

By Didactic Design (D-design) we understand designing and scientifically-methodical activity of the teacher at the creating of learning systems of new generation, innovative programs of training, actual educational resources, including electronic resources.

Productive carrying over of the creating object image into the field of D-design is accompanied by prolongation on it of four requirements groups from design: functional, aesthetic, ergonomic and social-economic. Their adaptation is concrete and also has the design character [19]. The functional aspect of D-design has to be connected with model of the future professional work of the graduate. In ergonomic requirements to objects of designing of the pedagogical nature it is necessary to be guided, first of all, on the psychological characteristics. The social-economic part of the object of D-design can be estimated by efficiency of introduced system, or project, or technology on positive changes of quality indicators of training.

So, the D-design needs to be considered as the technology of psychological-pedagogical designing aimed at achievement of following qualities of again created training objects and processes: student-centered orientation, integrity and efficiency.

\section{THE REQUIREMENTS FOR DESIGN OF THE DIDACTIC SYSTEM}

So-called environment-based approach (E. Glaserfeld, J. Dewey, J.S. Manuylov, L.I. Novikova, V.A. Yavsin, etc.) $[24,25,26,27,28]$ was developed in pedagogics. It can be considered not only as a conceptual direction but also as technology of the mediated management of the person formation and development process. It is obvious, that for preparation of the engineers capable of creating innovative products, the educational environment of university should be developing all the time. In researches of N.K. Nuriev, L.N. Zhurbenko, S.D. Staryginoy [20] it is shown, that requirements for the graduate engineers prepared in the educational environment of a university, are within the following limits: minimum (reproductive) the graduate should satisfy requirements of a society economy at the moment, and maximum (productive) - to be a "creator" of a society development in a certain direction of engineering. Therefore the condition of the educational environment of university in many ways defines society development as a whole. Thus the didactic system (D-system) is a "locomotive" of development of the educational environment of university since its direct function consists in realization of the formation process of professional and personal qualities of the new generation engineers [20].

Now we shall elaborate on the basic property characteristic for any system. Let's proceed from a rule that each concrete updating of system has the quite certain opportunities in attainment of the aim. These opportunities are rigidly caused by the characteristics of this system. With reference to D-system V.P. Bespalko formulates this statement as "the law of preservation and names it as "the first and unique law in didactic, asserting, that ... everyone didactic process has quite certain basic opportunities on quality of formation of students knowledge, skills and experience during given time " [21].

It means that if we aim to receive results of training of a required level and qualities, we should develop the Dsystem, which functioning will ensure the necessary orientation and intensity of pedagogical process by means of D-design. Thus, the formation of readiness of the future engineer for innovative solving of complex professional problems is possible only in D-system, which will satisfy at least four requirements of D-design, prolonged from design culture and adapted to the training system.

The first requirement - D-system should be the open developing system. For this purpose the development program providing transition from the achieved level (prototype-1) to the new perspective one (prototype-2), determined by changes in the requirements to preparation of the engineers should be incorporated [20].

One of the offered "from above" mechanisms of updating of D-systems is the new generation of the educational standards, which have both advantages and disadvantages. According to comparing of several national standards by the CDIO (Conceiving-Designing-ImplementingOperating) Syllabus of Massachusetts Institute of Technology there are

\section{Advantages:}

- sets the requirements for quality of the engineer preparation, determining changes of engineering programs and its frame work (format); 
- reorients the environment of training from disciplinefocused to student-centered (the result of education is estimated not by disciplinary knowledge, but by the generated ways of thinking and activity);

- does not have the restrictions decelerating the development of engineering programs.

\section{Disadvantages:}

- descriptive character of the standards requirements allows to treat them variously, leaving open space for the subjective estimations;

- speed of the standards creation lag behind speed of development of engineering especially in those spheres of activity which are developing very fast, for example, information technologies, electronics, nanotechnologies, etc.

The development of educational environment of university occurs at the expense of designing the new prototypes of D-systems as follows. The preparation of the engineer occurs by training in disciplines determined by the standard. The educational activity is organized within the framework of each of them. Thus, each educational discipline is a component of training environment and a mean of purpose-result achievement, expressed through a required level of preparation, which is periodically corrected by new generation of the standards. Hence, educational discipline should be developing all the time. This development is carried out through the analysis of training results, forecast of changes in the contents and technology of training, designing of the following prototype of D-system. Researches and applied developments of teaching staff within the problem environment of professional activity play an important role in this process. They actualize the contents of training and motivate of the students' activity.

The development of discipline within the framework of preparation occurs on the spiral circuit [20], in which the phases of modeling, designing, constructing and operation are allocated (Fig. 1). On the first phase (modeling) - on the basis of changes of conditions and factors of engineering activity and occurrence of the new requirements to preparation of the engineers the changes of components of the working prototype- 1 of D-system are predicted, and the model of the following prototype- 2 is created. In the phase of designing the content and technological blocks of educational discipline within the framework of the prototype-2 are developed. The phase of constructing provides check (approbation) of the prototype- 2 (of the didactic project of educational discipline) and its updating on the basis of the received experimental data. The phase of operation consists of three stages: introductions, works and assessment of the D-system prototype- 2 in educational process of university. It is necessary to note, that the scheme presented on the Fig 1. corresponds to functional model ADDIE most popular in pedagogical design (Analyze, Design, Develop, Implement, Evaluate) [29, 30].

The second requirement. In modern conditions of variety approaches the D-system should be based on the system of knowledge-based, activity-based and competency-based approaches. These approaches developing substantially independently and having different purposes provide complete development of the student's personality in their system interaction [31].

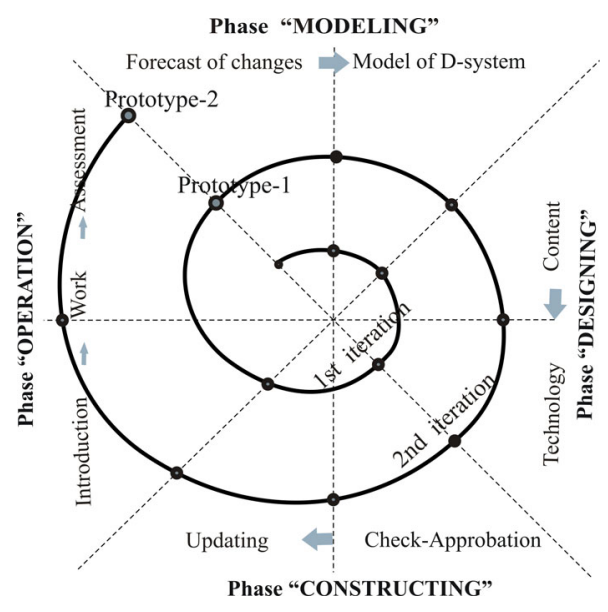

Figure 1. The spiral scheme of D-system development

Researchers mark that the creation of person-centered training environment through complete realization of the competency-based approach is reached [17, 32]. Within the framework of this approach the accents in an assessment from the input factors to development of the outcomes: knowledge, skills and competences claimed on the market of work are displaced. It conducts to the change of a teacher's role and in this connection to the necessity of development of new competences, other organization of training, which begins to be defined by inquiries of the students and should ensure growth of their self-activity.

Competence means "ability to apply knowledge, skills and personal qualities in the certain sphere of activity ", but before applying it is necessary to get these knowledge and skills. For this purpose today and in the future the knowledge- and activity-based approaches, which were mastered by educational practice will be necessary.

The third requirement. The projected D-system should be a system with virtual part [33] or real-virtual didactic system (RVD-system) [20].

With occurrence the Internet, the Intranet, the cellular network and wide distribution of information, communication and interactive technologies in all spheres of human activity the D-system, as a component of education system of a modern society, should use essentially new opportunities of organization of educational process in virtual environment. Among the traditional (classical) organizational forms of educational process today there is a distant form using Learning Management Systems (LMS) that realizes the concept of Virtual Learning Environments, and also various combinations of these forms - blended learning. Last variant is most preferable, as it combines advantages of both forms and compensates disadvantages of one form by the advantages of another, thus, expanding the didactic opportunities of D-system.

The formation of virtual part of D-system goes stage by stage. The originally available educational-methodical complex on discipline processes from paper variant into electronic. The questions of ergonomics and design are solved during this process: the texts are processed with the purpose of improvement of their perception from the screen of the computer, the information on the screen is divided into zones, the colors choice are executed according to the requirements of psychology and physiology, the static and dynamic illustrations are projected. Then the special tool means and environment for designing an electronic educational resource (EER) get out. In practice 
of engineering preparation there was a certain set of elements of EER: the electronic textbook, virtual laboratory work, tasks and exercises, tests, glossary, the biographic and help materials etc. It is necessary to note, that the content's development is a very labour-consuming work, which takes much of teacher time. Use of the special tools and environment of programming saves time, provides modern level of the functional and communication opportunities and user graphic interface, excludes many mistakes of the beginning developers. Therefore the choice of concrete environment of programming is very important.

The fourth requirement. The projected D-system should form environment of advancing preparation (outstripping training).

The advancing preparation provides such organization of training, in which the contents of vocational training and technology of its realization form future specialist's "zone of proximal" development (L.S. Vygotsky) [13]. That will allow them not only to adapt and to be asserted in the professional activity, but also will develop readiness for continuous perfection. For this purpose in the contents of education the accent from the achieved (actual) level of development of production, science and engineering should be transferred to the perspective (potential) level, then pedagogical technologies must be projected in view of constant updating of the contents.

\section{Didactic Designing of EdUCATIONAL Resource AS MeAns of Pedagogical SupPort of A STUdENT}

The necessity of selection and systematization of knowledge on the degree of its demand in professional activity arises in connection with the exponential growth of the new information amount, on the one hand, and the existing limit of a student's time for its acquiring, on the other hand. In pedagogics this process refers to as actualization of the contents of training. As the content of training refers to the certain field of knowledge, its actualization has to be considered in a concrete discipline. Electronics that is a basis for many engineering specialties and directions of preparation is especially obvious example. Modern achievements in electronic science and technics significantly changed practical application of electromagnetic phenomena in most of manufacturing, agricultural and transport companies and now they determine their development. However, changes of the electronics education lag behind development rates of engineering in that field. Let's refer to an example.

Generalization of pedagogic experience of electronics teaching in different institutes revealed that the main attention is paid to the semiconductive elements, analog and digital nonprogrammable devices. At the same time modern production of electrical technics is based mainly on the microprocessors, it is also reflected in scientific and popular science literature. There is a paradox: a graduate studied electronics cannot understand the functioning system of microcontroller-based device. By the way, microcontroller is considered as the most outstanding achievement in electronics after transistor. We add that scientific works with technical decisions based on microcontroller win the competitions (according to the experts' responses). Analog and nonprogrammable digital devises lose their ground for perspective programmable systems microcontrollers.

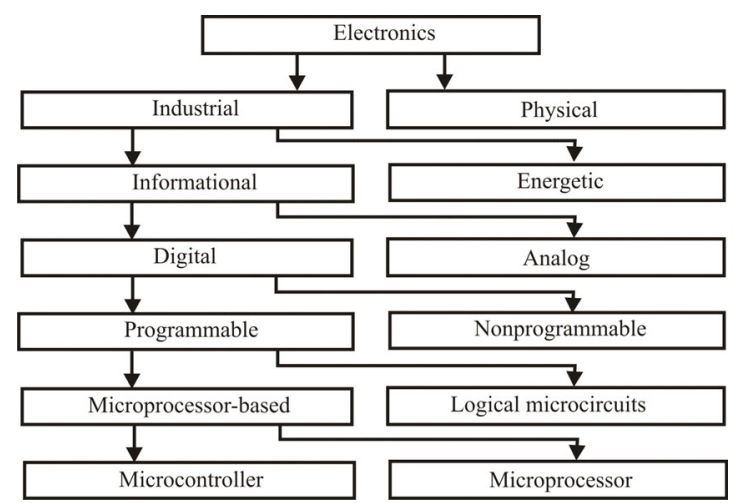

Figure 2. Structure of electronics

The analysis of textbooks, scientific literature and Internet allowed us to form the structure of modern electronics (Fig. 2) $\lceil 34,35,36,37,381$.The laboriousness of modules study (academic loading of students) depends on the direction of training and specialization.

We do not deny the importance of studying basic electronics, but, as a rule, these basics are well developed and their acquiring by student himself under the guidance of a teacher does not present a difficulty. Didactic problems connected with the study of microcontroller require the decision; we offer one in the form educational resource.

We consider educational resource as a complex of training means intended for pedagogic support to student in self-acquiring a field of knowledge.

What is the understanding of "training means" today? S.G. Shapovalenko classifies as means of training different material objects including artificially made especially for educational purposes and ones that are involved into the learning process as a carrier of training information and a tool of teacher and student activity [39]. P.I. Pidkasisty [40] added to the training means the ideal objects. S.A. Smirnov [41] defines training means as a key link, and V.E. Shteinberg defines them as an instrumental basis of educational technology [18]. Prospect of training means development was predicted in 1972 by E.W. Dijkstra and C.A.R. Hoare, whose contribution to a science is so deep and original, what even after decades their works remain actual. They specified that computer and programming are extremely flexible and powerful tool expanding intellectual possibilities of the person in all fields of activity, including educational [42, 43]. These instruments give modern training means new qualities - multimedia and interactivity $[33,44]$. N.E. Rubtsova and S.L. Lenkov in their researches of psychological means of the teacher's professional activity in area of information technologies distinguished three groups of training means: 1) external (object); (2) external functional (psychological); (3) internal (psychological) [45].

There are close links between external and internal training means. Any external means can be fixed as model, form, description or it may be interiorizated (transition from the outside into inside - psychological concept is entered L.S. Vygotsky) by means of its active reflection in the mind. The interiorizated external means is not a copy in the person mind, it includes many additional elements and their links caused by knowledge, experience, thesaurus, psychical features and man's actualized psychical processes. Therefore, the interiorizated external means is rather independent phenomenon, though it is 
generated by an external means. Moreover, external means can contain means that do not directly connected with external object actions and tools of work, i.e. additional psychological structures promoting perception and memorization are created. Hence N.E. Rubtzova and S.L. Lenkov conclude that the system of the internal training means is much more diverse and complicated than the system of external ones [45]. Therefore we can significantly influence on the expansion of the system of person's internal means by managing the development of the external means. This is meant to be pedagogic support for a student in acquiring actual content.

We used systematization introduced by S.A. Smirnov that is based on V.V. Kraevskiy statement that training content is a "system forming" element [46]. So two big groups of training means can be defined: (1) means as informational source and (2) means as a tool for its acquiring and processing.

With regard to the study of microcontroller we developed educational resource (ER) - training-methodical and hardware-software complex shown in the Fig. 3. Trainingmethodical part of the complex is represented in a teaching manual [47]. How was solved the problem of actualization of its content?

The manual is aimed to provide selected from many sources and systematically organized material to mechanical, electrical students, who do not have special skills in programming, to acquire the opportunities of modern electronics, which element base includes programmable systems located in one semiconductive crystal - microcontrollers.

In educational process industrial electronics is divided into two components according to the module principle: informational and energetic (Fig. 2). Informational electronics forms the basis for computing, measuring and control technics and for automatic devices. It includes devices for reception, processing, transmission, storage and usage of information. Microcontrollers are focused on performance of these functions. Energetic electronics is connected with devices and systems for conversion of electric energy such as rectifiers, invertors, powerful frequency converters and others. These devices also operate under control of microcontroller.

The authors while doing research and developing application in the field of informational electronics made an analysis of patent-information search. So they received evidence that information and measurement devices take the first place by frequency and the effectiveness of the application of microcontroller. With the emergence of microprocessors the principles of measuring and control systems designing changed cardinally. The microprocessor, built into a measuring device, imparts new properties to it: multifunctionality, self-calibration, automatization of statistical analysis of measurements, increasing of effectiveness, reliability and safety, it also allows solving problems that were not even set earlier [48, 49, 50]. Therefore it is advisable to organize study of microcontroller based on the examples of information and measurement devices designing.

While drawing up the manual we pursued the following objective. Described material has to be useful in solving student's and graduate's projects, in writing dissertation and research-scientific works where the questions related to the measurement of physical properties and quantities

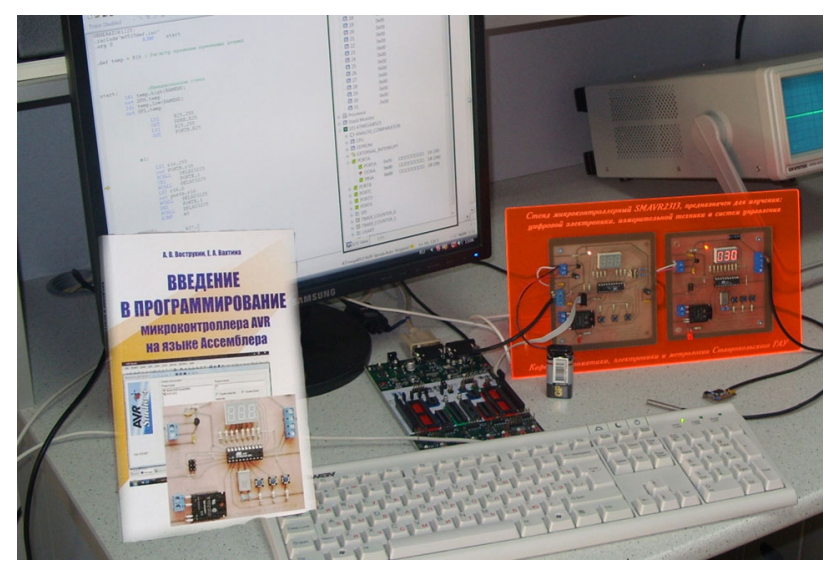

Figure 3. Educational resource for programming microcontroller

are mentioned. Meanwhile considering measurement devices has to be claimed in practical activity, accessible in understanding and to function with the help of simple programs. "Intellectual sensors" - microcontroller's measuring converters constructively designed in one casing together with primary sensor - can be an example of such device.

In order to develop microcontroller-based device a student has to choose the most appropriate microcontroller, to connect it with sensors, keyboard, indicator, keys, organize interface with other microprocessor-based devices, if necessary, and to develop the most labourconsuming part of the device - a program. At the initial stage it is better to use Assembler computer language. This language in comparison with others, C for example, let student think in terms of digital electronics. It provides realization of the principle of continuity in education. In addition, Assembler is one of the best tools (besides mathematics) developing logic and creating conditions for student creative activity.

What microcontroller is better to study? According to the data of Internet quizzes AVR microcontrollers by Atmel Corporation are the most popular among hardware designers. By the ratio of price-efficiency-power consumption they are world leaders and industrial standard [48].

There are a lot of manuals about AVR microcontrollers now where you can find examples of structures of different devices. However, the majority of them do not implement typical functions of information and measurement systems. Examples of programming of such functions, like conversion of physical properties and quantities into digital code, data input from sensors and keyboard, data output on the indicator, formation of managing signals by executive devices, etc. are carried out in the our manual in order to fill this lack.

Hardware-software block of ER consists of developed programs and hardware for their realizations - microcontroller test bench (Fig. 3). Test bench is designed in two modules with digital and analog inputs [51]. Fig. 4 shows module structure with the digital one. Each module has a slot for programming microcontroller with the help of AVRISP mkII programmer connecting with computer through USB port. The main purpose of hardwaresoftware block of ER in training process is realization of practical component in studying microcontroller programming. 
We offer tests, training tasks for self-managed learning for fastening student knowledge and skills of programming. Examples of fulfilled tasks are represented in the form of full-text programs of typical functions of information and measurement systems.

Assessment of performance of the above-named (design of D-system) requirements was carried out by results of experimental approbation ER by the criteria proved in [52]: change of integration qualities of knowledge efficiency (the first requirement), systemacity (the second requirement) and reliability (the fourth requirement); definition of optimality ER on its ergonomic qualities (the third requirement). Two groups of students were chosen for this purpose - experimental one where the developed ER was used in the process of learning, and control one where ER was not applied.

Changes in sample averages of corresponding factors were used as indicators of changes in integration qualities of students knowledge: $\mathrm{K}_{e}^{a v}$ efficiency, $\mathrm{K}_{s}^{a v}$ systemacity and $\mathrm{K}_{r}^{a v}$ knowledge reliability and their selective dispersion $\sigma_{e}^{2}, \sigma_{s}^{2}$ and $\sigma_{r}^{2}$. All indicators were defined by the methods of mathematical statistics as the selective moments of distribution of students from each group by corresponding factor. The latter was defined experimentally by the selective standardised (test) control of didactic units of learning module "Microcontrollers" of "Electronics" discipline.

As an example Fig. 5 and 6 results shows the results of control of knowledge systemacity factor $K_{\mathrm{s}}$ of students in the form of histograms and the extrapolation curves obtained by a method of the least squares are presented. From Fig. 5 and 6 follows, that this factor for experimental and control groups essentially differs not only quantitatively ( $\mathrm{K}_{s}^{a v}$ in an average above), but also qualitatively (on distribution density).

To detect ergonomic qualities of ER, we additionally investigated its influence on cognitive activity of students.

As the parameter defining cognitive activity, we used the indicator of performance by students of a group of all kinds of educational activity $\Pi_{a}$ which was calculated

from the formula:

$$
\Pi_{\mathrm{a}}=\frac{\grave{A}}{N \cdot T},
$$

where $A$ - quantity of the works executed by students; $N$ - quantity of students in a group;

$T$ - time allocated for studying the discipline according to the academic curriculum in hours $\left(\Pi_{\mathrm{a}}=\right.$ hour $\left.^{-1}\right)$.

All kinds of works provided by the program, and also participation in Olympiads, learning projects and scientific researches were registered. Registration was performed during educational process in both groups.

The sample averages of the cognitive activity indicator $\Pi_{\grave{a}}^{a v}$ of experimental and control groups was equal to 0,84 hour $^{-1}$ and 0,73 hour ${ }^{-1}$ respectively, that confirms significant improvement of this indicator. Having distributed all educational tasks executed by students by levels of cognitive activity: reproductive, productive and creative, we detected, that $\Pi_{\grave{a}}^{a v}$ increased due to the increasing number of works of productive and creative levels.

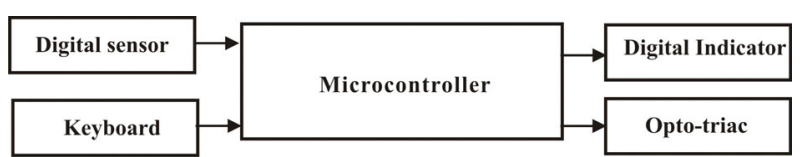

Figure 4. Structure of module of microcontroller test bench
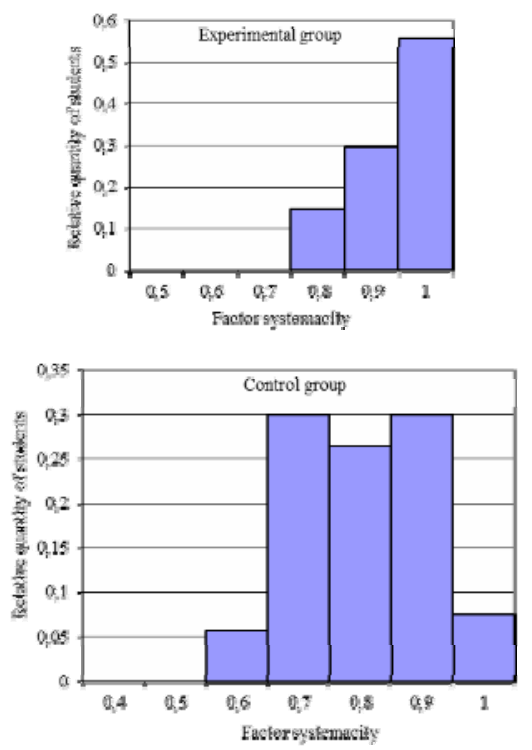

Figure 5. Histograms of students distribution by Ks

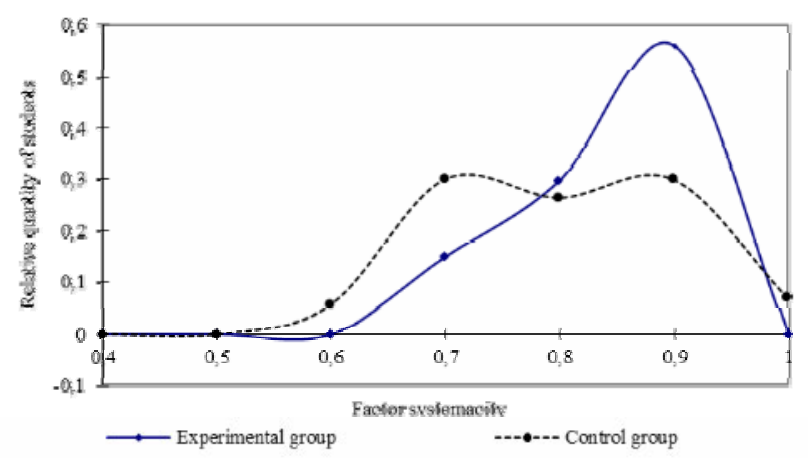

Figure 6. Density of students distribution by Ks

Besides, $67 \%$ of the respondents participated in experiment noticed, that «application of ER created convenient conditions for performance of autonomous work, as well as stimulated desire to study new material more intensely».

\section{CONCLUSION}

Thus, we can see that teacher choosing actual content of training solve the problem of pedagogic support tools for its acquiring: by choosing perspective means, projecting and creating new ones. This is very important for the development of modern educational practices. Educational resource can be considered only as combination of its content and tools for its acquiring: studying, training, control, self-control, since only in this case it gives to the students necessary and sufficient conditions for acquiring some subject area required in his professional and social activity irrespective of time and place.

A number of control and measurement devices were developed and patented during approbation and application of ER in scientific and educational process [53, 54, 
55, 56, 57]. All programs for these devices and systems were developed in AVR Studio environment. Its new version is available on the Atmel company web-site www/atmel.com or on Russian web-site www/atmel.ru. AVR Studio programming environment is freely available. That is rather significant fact for realization of educational resource.

In conclusion we emphasize that ER for microcontroller programming developed by the authors is a system of actual content represented in the manual in form of practice-oriented task with didactic support of solving and tools - programming environment and language, the set of programs of typical functions of information-measurement systems and microcontroller test bench (laboratory). So, questions of innovative products development in education in frames of D-systems of new generation can be solved by means of D-design.

The correctness of the accepted decision is indicated by examples from modern educational practice in studing microprocessor devices and systems [58, 59, 60, 61].

In general, educational resources developed for formation of competence in the area of design and applications of microprocessor-based equipment are in demand in modern engineering education. Each of existing Russian and foreign scientific schools offers its own solution for design of resources like that. The best ones will be determined by conformity of their didactic opportunities with modern requirements of engineers' preparation and ergonomic requirements.

\section{REFERENCES}

[1] Pokholkov, Y.P. The basic principles of the national doctrine of engineering education / Y.P. Pokholkov, B.L. Agranovich // Tomskpolytechnical university, 2000, pp 2-3.

[2] Melezinek A. IGIP and the Trends in Engineering Education / A.Melezinek, M. Auer // Higher Education in Russia. - 2011. - № 12. - pp. 36-39.

[3] Belyaev, G.J. Formation of the term "educational environment" in the psychological - pedagogical literature of the end XX - beginning XI century. Available at http://dzd.rksmb.org/ science/bel06.htm (Accessed 25.08.2012).

[4] Pearlman, B. Designing New Learning Environments to Support 21 st Century Skills. Available at http://www.bobpearlman.org/ Learning21/New\%20Learning\%20Environments\%20for\%2021 st \%20Century\%20Skills.PDF (Accessed 30.08.2012).

[5] Robotova, A.S. The features of the modern pedagogical discourse / A.S. Robotova // Higher Education in Russia. - 2011. - № 7. pp. 9-19.

[6] 21st Century Learning Environments. Partnership for 21st Century Skills Framework. Available at http://www.p21.org/storage/ documents/le_white_paper-1.pdf (Accessed 27.08.2012).

[7] Brown, J. S. New Learning Environments for the 21st Century. Available at http://www.johnseelybrown.com/newlearning.pdf (Accessed 29.08.2012).

[8] Gushchina, T. N. The analysis of the educational sphere as a means of development of the senior pupil's subjectivity /T. N. Gushchina // The Yaroslavl pedagogical bulletin. - 2010. - № 2. pp. 17-22.

[9] Skinner, B. F. The science of learning and the art of teaching B. F. Skinner // Harv. educ. Rev., 1954.

[10] Bloom, B. S. Taxonomy of Educational Objectives (1956). Published by Allyn and Bacon, Boston, MA. Copyright (c) 1984 by Pearson Education.

[11] Piaget, J. Cognitive development. Available at http://www.simplypsychology.org/piaget.html (Accessed 31.08.2012).
[12] Clark, R.C., Mayer, R.E. E-Learning and the Science of Instruction: Proven Guidelines for Consumers and Designers of Multimedia Learning. San Francisco: Pfeiffer., 2002.

[13] Vygotsky, L.S. Pedagogical psychology / Under the editorship of V.V. Davidov. - M: Pedagogics-Press, 1996. - pp. 10-19.

[14] Bruner, J.S. Processes of Cognitive Growth / J.S. Bruner // M.: Progress, 1977. - p. 320. Actual Minds, Possible Worlds. Cambridge, MA: Harvard UP, 1986. -222 p.

[15] Palincsar, A.S. Social constructivist perspectives on teaching and learning/ A.S. Palincsar // Annual Review of Psychology, 1998. pp. 49, 345-375.

[16] Siemens, G. Connectivism: A Learning Theory for the Digital Age / G. Siemens // December 12, 2004. Available at http://www.elearnspace.org/Articles/connectivism.htm (Accessed 12.06.2010).

[17] Verbitsky, A.A. Competency-based approach and the theory of contextual training / A.A.Verbitsky// - M: IC PKPS.-2004. - 84 p.

[18] Shteynberg, V.E. Didactic multidimentional tools: the theory, technique, practice / V. E. Shteynberg. - M.: National education, 2002. - p. 12-13.

[19] Klimov, V. P. The versions and principles of design-education / V. P. Klimov // Functioning of college as uniform learn-researchproduction complex: the collection of scientific materials of the Russian conference - M.: OOO "AvtoPrint", 2010. - pp. 74-78.

[20] Nuriev, N.K. Designing of new generation didactic systems for preparation of engineers capable of innovative activity / N.K. Nuriev, L.N. Zhurbenko, S.D. Starygina, E.V. Pashukova, A.R. Akhmadeeva // Educational technologies and a society. - 2009. №12. - pp. 417-440.

[21] Bespalko, V.P. Bases of the pedagogical systems theory: problems and methods of psychological-pedagogical maintenance of didactic systems technology / V.P. Bespalko - Voronezh: Publishing house of the Voronezh University, 1977. -136p.

[22] Gagné, R.M. Instructional Design, Conditions of Learning / Gagné R.M. // Available at http://www.instructionaldesign.org/theories/ conditions-learning.html (Accessed 04.09.2011). Gagné R.M. etc. Principles of instructional design. : Thomson/Wadsworth, 2005.$416 \mathrm{p}$.

[23] Polman, J.L. Designing project-based science: Connecting learners through guided inquiry/ J.L. Polman // New York: Teachers College Press, 2000.

[24] Hickman, L. A. John Dewey Between Pragmatism and Constructivism / L. A. Hickman, Neubert S., Reich K. // Fordham University Press, 2009. - 288 p. http://dx.doi.org/10.5422/fso/97808232 $\underline{30181.001 .0001}$

[25] Glaserfeld, E. Constructivism in education / E. Glaserfeld // Oxford England: Pergamon Press, 1989. - 162 p.

[26] Manuylov J.S. The Environmental Approach in Education / J.S.Manuylov// 2 issue, the processed. - M; N.Novgorod: publishing house Volgo-Vjatskoj Academy of State Service, 2002. - 157 p.

[27] Novikova, L.I. School and Environment / L.I. Novikova // M: Knowledge, 1985. - 80 p.

[28] Javsin, V.A. Educftion Environment: from modelling to designing / V.A.Javsin// - M: Sense, 2001. - 365 p.

[29] Branson, R.K., Rayner, G.T., Cox, J.L., Furman, J.P., King, F.J., Hannum, W.H. (1975). Interservice procedures for instructional systems development. (5 vols.) (TRADOC Pam 350-30 NAVEDTRA 106A). Ft. Monroe, VA: U.S. Army Training and Doctrine Command, August 1975. (NTIS No. ADA 019486 through ADA 019 490).

[30] Duffy, T.M. \& Jonassen, D.H. Constructivism: New implications for instructional technology. In T. Duffy \& D. Jonassen (Eds.), Constructivism and the technology of instruction. - Hillsdale, NJ: Erlbaum, - 1992. - pp. 1-16.

[31] Reigeluth, C. M. Educational systems development and its relationship to ISD. In G. Anglin (Ed.), Instructional technology: Past, present, and future $\left(2^{\text {nd }}\right.$ ed.). Englewood CO: Libraries Unlimited, 1995. - pp. 84-93

[32] Arun, S.P. Engineering Education Quality Assurance: A Global Perspective / S.P. Arun, P. J.Gray // - London. Springer Science+Busines Media LLC, $2009-316$ p. 
[33] Aldrich, C. Simulations and the Future of Learning: An Innovative (and Perhaps Revolutionary) Approach to e-Learning / C. Aldrich // John Wiley \& Sons, 2003. - 304 p.

[34] Bases of industrial electronics: the Manual for Higher schools / under the editorship of V.G. Gerasimov. - 3 ed. - M: Higher school, $1986-336 \mathrm{p}$.

[35] Kovalenko, A.A. Bases of microelectronics: the Manual / A.A. Kovalenko, M.D. Petropavlovsky. 2 ed. - M: Academy, 2008. 240 p.

[36] Laboratory «Expanded course of electronics» of the company «Degem Systems Holdings LTD». Available at http://www.degem.com/index.php?option=com_content\&view_art icle\&id=283\&Itemid=348lang=ru (Accessed 14.07.2011).

[37] All about Circuits. Available at http://www.allaboutcircuits.com/ Accessed (11.09.2011).

[38] Ibrahim, K. F. Electronic Systems \&Technigues / K. F. Ibrahim // $\left(2^{\text {nd }}\right.$ ed.) Publisher: Longman Publishing Group, London, 1994. $295 \mathrm{p}$.

[39] Shapovalenko, S. G. School equipment and room system, in the book:Questionsof school-conducting. - M., 1982. About studying andapplication in high schools of computing, microprocessor technics and programming. Available at http://www.voppsy.ru/ issues/1983/834/834011.htm (Accessed 17.07.2012).

[40] Pidkasistyj, P.I.The psychological-didactic directory of the teacher of the higher school / P.I. Pidkasistyj, L.M. Fridman, M.G. Garunov. - M: Pedagogical society of Russia, 1999. - 354 p.

[41] Smirnov S.A. Once more about educational technologies / Smirnov S.A. // Higher education in Russia. - 2000. - №6. - pp. 116-118.

[42] Hoare, C.A.R. Programming as an engineering profession // Microprocessor means and systems. - 1984. - №4. - pp. 53-60.

[43] Dijkstra, E.W. Selected articles. Transfer has executed Alf (alf63@list.ru<mailto:alf63@list.ru>). The primary source: http://shelek.com/ Available at http://www.inr.ac.ru / info21/pdf/ dijkstra.pdf (Accessed 16.09.2012).

[44] Hill, J. R. Teaching and Learning in Digital Environments: The Resurgence of Resource-Based Learning / J.R. Hill, M. J. Hannafin // Educational Technology, Research and Development (ETR\&D). - 2001. - Vol. 49, No. 3. Available at http:// www.deanz.org.nz/home/home/images/2012Conference/Michael \%20Barbour/hill-hannafin.pdf (Accessed 07.09.2011).

[45] Rubtzova N.E. Psychological means in the professional activity of information technologies teacher / Rubtzova N.E., Lenkov S.L.// Open education. - 2002. - №4. - p.27.

[46] Kraevsky, V.V. Pedagogics bases: the textbook for students of the higher pedagogical educational institutions / V.V. Kraevsky. - M: Publish. Centre "Academy", 2003. - 256 p.

[47] Vostrukhin A.V. Introduction to the AVR microcontroller programming in Assembler language: teaching manual / Vostrukhin A.V., Vahtina E.A. $2^{\text {nd }}$ edition revised and expanded Moscow.: Ileksa, 2010. - 184p.: ill.

[48] Grebnev V.V. Microcontrollers of AVR family, Atmel company / Grebnev V.V. - Moscow: RadioSoft, 2002. - 176p.: ill.

[49] MirskyG.Ya. Microprocessor in measuring devises / MirskyG.Ya.- Moscow: Radio and communications, 1984. - 160p., ill.

[50] Trampert V. Measurement, management and regulation by AVRmicrocontroller.: Transl. from German / Trampert V. - K.: MKPress, 2006. - 208p., ill.

[51] Pat. 75507 Russian Federation, IQIS $^{9}$ 14-02. Microcontroller test bench / Vostrukhin A.V., Vahtina E.A.; applicant and patent holder is FSBEE HPE StavropolSAU. - №2009501267; appl. 12.05.2009; publ. 16.07.2010, - 5p.
[52] Vakhtina, E.A. Didactic designing as technology of humanization of training process in higher school: dissertation of $\mathrm{Ph} . \mathrm{D}$. in pedagogical sciences 13.00.08 / Vahtina Elena Arturovna. - Stavropol, 2006. $-228 \mathrm{p}$.

[53] Pat. 2378658 Russian Federation, IPQ G01R 27/26. The microcontroller device for measurement of rotation frequency of the shaft / Vostrukhin A.V., Vahtina E.A., Doroqko S.V.; applicant and patent holder is FSBEE HPE Stavropol SAU. №2008137462/28; appl. 18.09.2008; publ. 10.01.2010, Bul. № 1 .

[54] Pat. 2392629 Russian Federation, IPQ G01R 27/26. The microcontroller device for capacitor and resistance measurement / Vostrukhin A.V., Vahtina E.A.; applicant and patent holder is FSBEE HPE Stavropol SAU. - №2009121938/28; appl. 08.06.2009; publ. 20.06.2010, Bul. № 17.

[55] Pat. 2392629 Russian Federation, IPQ G01R 27/26. The microcontroller device for research of dielectric properties of biological objects and isolation materials / Vostrukhin A.V., Danilov K.P., Vahtina E.A.; applicant and patent holder is FSBEE HPE Stavropol SAU. - №2009129778/28; appl. 03.08.2009; publ. 27.07.2010, Bul. № 21 .

[56] Pat. 2428707 Russian Federation, IPQ G01R 31/06. The microcontroller device for diagnostics of a winding isolation of the induction motor / Vostrukhin A.V., Danilov K.P., Vahtina E.A.,Doroqko S.V.; applicant and patent holder is FSBEE HPE Stavropol SAU. - №2010115925/28; appl. 21.04.2010; publ. 10.09.2011, Bul. № 24 .

[57] Pat. 2449299 Russian Federation, IPQ G01R 27/00. The microcontroller measuring converter for the resistive sensorVostrukhinA.V.,Yadikin V.S., Habarov A. N., Vahtina E.A.; applicant and patent holder are the authors. - №2011102153/28; appl. 20.01.2011; publ. 27.04.2012, Bul. № 24 .

[58] Hartov V. Y. Microcontrollers AVR. A practical work for beginners. - M: Publish. house of MGTU of N.E. Bauman, 2007. -240 p.

[59] Revich J.V. Practical Programming of Microcontrollers Atmel AVR in Assembler Language - SPb.: BHV-Peterburg, 2008. $384 \mathrm{p}$.

[60] Bondarenko V. Training Complex for Remote Study of Microcontrollers / V. Bondarenko // Supplement to International Journal "Information Technologies \& Knowledge" Volume 2 / 2008. - pp. $59-62$.

[61] Somatri Y., Juanda E.A., Haritman E. Design and Implementation of Microcontroller Trainer as Interactive Media to Enhance Learning Process in Vocational Schools (Indonesia: SMK). Available at http://file.upi.edu/Direktori FPTK/JUR. PEND. TEKNIK_ELEKTRO/195508261981011-NJANG_AHMAD_JU ANDA/scientific article MCsplus eaj_yy_er_ENJANG_A_ J UPI.pdf (Accessed 17.09.2012)

\section{AUTHORS}

E.A. Vahtina is with the Department of Automatics, Electronics and Metrology, FSBEE HPE Stavropol State Agrarian University, Russia,355017, Stavropol, Zootechnichesky Lane 12, (e-mail:vea1961@ya.ru).

A.V. Vostrukhin is with the Department of Information Technologies and Electronics, FSBEE HPE Stavropol Technology Institute of Service, Russia, 355035, Stavropol, Kulakovaprospectus 41/1, (e-mail: avostrukhin@ya.ru).

Received 2 October 2012. Published as resubmitted by the authors 18 December 2012. 